\title{
Emergent achievement segregation in freshmen learning community networks
}

\author{
Jasperina Brouwer ${ }^{1}$ • Andreas Flache ${ }^{2}$ - Ellen Jansen $^{3}$ • \\ Adriaan Hofman $^{3}$ - Christian Steglich Ch $^{2,4}$
}

(C) The Author(s) 2017. This article is an open access publication

\begin{abstract}
A common assumption about Freshmen Learning Communities (FLCs) is that academic relationships contribute to students' success. This study investigates how students in learning communities connect with fellow students for friendship and academic support. Longitudinal social network data across the first year, collected from 95 Dutch students in eight FLCs, measure both social and academic relational choices within and beyond the FLCs. Using stochastic actor-based models, the study tests two competing hypotheses. The alignment hypothesis states that students connect with their similar-achieving friends for both academic and social support, leading to an alignment of both types of networks over time. In contrast, the duality hypothesis states dissimilarity between academic support networks and friendship networks:
\end{abstract}

Jasperina Brouwer

jasperina.brouwer@rug.nl

Andreas Flache

a.flache@rug.nl

Ellen Jansen

e.p.w.a.jansen@rug.nl

Adriaan Hofman

w.h.a.hofman@rug.nl

Christian Steglich

c.e.g.steglich@rug.nl

1 Department Educational Science, Faculty Behavioural and Social Sciences, University of Groningen, Grote Rozenstraat 3, 9712 TG Groningen, The Netherlands

2 Department of Sociology ICS, Faculty Behavioural and Social Sciences, University of Groningen, Grote Rozenstraat 31, 9712 TG Groningen, The Netherlands

3 Teacher Education, Faculty Behavioural and Social Sciences, University of Groningen, Grote Kruisstraat 2/1, 9712TS Groningen, The Netherlands

4 Institute for Analytical Sociology, Linköping University, Kopparhammaren 2 Norra Grytsgatan 10, 60174 Norrköping, Sweden 
students should connect with better-achieving fellow students for academic support and to more similar peers for friendship. The data support the alignment hypothesis but not the duality hypothesis; in addition, they show evidence of achievement segregation in FLCs: the higher the students' achievement level, the more they connect with other students for both academic support and friendship, relating in particular to peers with a similarly high achievement level. The results suggest that lower-achieving students are excluded from the support provided by higherachieving students and instead ask similar lower achievers for support. They thus cannot benefit optimally from the academic integration FLC offer. The article concludes with recommendations of how to support students in an FLC so that they can reach optimal achievement potential.

Keywords Learning communities · Academic support networks · Friendship - Achievement · Self-efficacy $\cdot$ Network dynamics

\section{Introduction}

Contemporary university curricula increasingly encourage students to develop social and academic relationships with academic peers (e.g., Brown et al. 2014; Celant 2013; Etcheverry et al. 2001); in a similar vein, research deems these relationships crucial for adjustment to universities (Christie et al. 2004; O’Donnell 2006; Rausch and Hamilton 2006). Universities have increasingly implemented Freshmen Learning Communities (FLCs) as a learning environment in which peer interaction among first-year students is facilitated. In FLCs, a cohort of first-year students is divided into small groups, approximately 12-14 students, who jointly move through the whole program during the first semester or first year. The expectation is that during and outside class, FLC members discuss study material, undertake collaborative assignments, ask and give one another help, and also become friends (e.g., Smith et al. 2004; Talburt and Boyles 2005; Tinto 1998, 2000; Zhao and Kuh 2004).

Several studies investigate the direct and indirect effects of self-perceived interaction with fellow students on study success (e.g., Brooman and Darwent 2014; Christie et al. 2004; Torenbeek et al. 2010; Meeuwisse et al. 2010; Severiens and Wolff 2008). However, few studies address what determines students' academic support relationships in a FLC and how they are connected by social relationships with peers. In particular, more insight into the process of academic and social relationship formation is necessary, because whether and under what conditions social relationships reinforce academic relationships in FLCs or, alternatively, may develop independently or sometimes even hinder effective academic support remain open questions. To clarify the relationships between academic and social networks in an FLC, we use longitudinal social network data to measure perceptions of the relationships and interactions among all students simultaneously over time in several FLCs. We analyze our network data with stochastic actor-based models (Snijders 2001, 2005), a statistical method that allows us to distinguish simultaneous dynamics of network formation and their relationship to student characteristics, moving beyond prior studies of network dynamics in higher-education classrooms that employ correlational methods (Rienties et al. 2013).

\section{Academic and social support relationships}

Proponents of learning communities distinguish between students' integration into the academic system and into the social system (Smith et al. 2004; Tinto 1993, 2000). More recently, researchers have proposed conceptualizing these two forms of integration in terms of students' 
embeddedness in networks of interpersonal academic and social relationships with fellow students (Smith 2015). In social networks, similar to friendship networks, relationships are not necessarily study-related or task-dependent but rather provide personal and emotional support, which may reduce stress or ease problematic situations (e.g., Zhu et al. 2013). We define social support as emotional support and affection from friends, which serves as an important buffer against stress after the transition to universities (Buote et al. 2007; Wilcox et al. 2005). In academic networks, relationships among students are characterized as study-related, task dependent, and associated with academic support (Nebus 2006; Tomás-Miquel et al. 2015). These relations can make an important contribution to students' success (Gaševic et al. 2013; Thomas 2000). We define academic support as instrumental or informational support that helps students in their learning process and in meeting academic requirements (e.g., borrowing a book or receiving advice from a fellow student).

Studies show that willingness to help and expertise are important determinants of effective support and advice relationships in organizational networks (Cross and Borgatti 2004). In line with this reasoning, in student networks achievement signals academic capability and expertise. Students with good grades are likely to have study-related information valuable for academic success of the recipients. In addition, another signal of expertise is academic self-efficacy (Kraft et al. 2005 call this "I-can-do" cognitions), or the belief in one's capability of accomplishing a given level of achievement (e.g., Bandura 1997), which is related to study success (Brouwer et al. 2016a; Feldman and Kubota 2015; Richardson et al. 2012). Highly self-efficacious students may be attractive as helpers and advice givers but may also make others feel uncertain. In challenging situations, students may feel more comfortable interacting with someone with similar feelings or beliefs (Townsend et al. 2014). We explore how academic achievement and self-efficacy affect choices in academic support and advice relationships in an FLC.

An academic relationship depends on both the help seeker and the help giver. Social exchange theory postulates that individuals select exchange partners from whom they expect the most valuable returns for their investment in supporting the partner (e.g., Blau 1964; Cook and Rise 2003; Homans 1961). For example, lower-achieving students may benefit most from advice from a higher achiever, but what is a valuable return for the higher-achieving student? One possibility is that low achievers "pay back" in terms of friendship support. However, such an asymmetric exchange would be at odds with one of the most robust regularities established by studies of friendship networks: the homophily or similarity principle (Flashman 2012; Lomi et al. 2011; McPherson et al. 2001). This principle suggests that friends are likely to be similar not only in important background characteristics, such as gender, but also in other characteristics, such as their achievement level. Friends also are likely willing to help one another, but low-achieving students in particular may not receive the best help from their similarly lowachieving friends. Higher-achieving students, in turn, may be unwilling to give support or advice to low achievers unless they have a personal relationship with them (Nebus 2006). This predicament gives rise to the following question: with whom do first-year students connect when they need academic support or advice? Do they ask a higher-achieving student who is not a friend, or do they ask a similar-achieving friend who is not an "expert" but is willing to help?

\section{Achieving academic goals: alignment or duality?}

Although Tinto revised the conceptualization of social and academic integration over time (see Beekhoven et al. 2002), the key aspect is that relationships may be important for academic 
success. Tinto's $(1975,1993)$ model suggests that circumstances should be most optimal for academic success when integration in the academic system is aligned (i.e., balanced) with integration in the social system. From this perspective, students' relationships with friends can be a major source of not only their social (non-study-related) goals but also their academic goals. If students do combine social and academic goals in their relational choices in an FLC, the strong role of the homophily principle in friendship formation would suggest that they prefer to ask their similar (-achieving) friends for academic support rather than another dissimilar fellow student. One reason is that students may feel more comfortable asking a friend, particularly when they start at a university and feel uncertain. While this may appear to be at odds with optimization of the quality of advice received, research on organizational networks shows that even bankers facing financially risky decisions turn more to their friends for advice than to more knowledgeable but socially more distant colleagues (Mizruchi and Stearns 2001). In addition, crosssectional studies show that friendship and academic networks strongly overlap for university students (Chen et al. 2012). Thus, we test the alignment hypothesis that relationships in the social system (friendships) and in the academic system (help seeking and preference for collaborators) in FLCs are linked to each other over time in the way that Tinto's theory would see as optimal for academic progress. We expect in addition that students who are similar in achievement and self-efficacy are more likely to establish both academic and social relationships with each other.

Vygotsky's social constructive theory suggests a somewhat different view on relational patterns in an FLC. According to this perspective, students' learning or cognitive growth should benefit most from peer interaction with an advanced peer in the "zone of proximal development," which suggests that a less capable student can achieve better with assistance and guidance from a more capable fellow student (Aleven et al. 2003; Vygotsky 1978). In academic support relationships, students should thus be moderately dissimilar in their achievement level or capabilities, because higher achievers can function as a "scaffold" for lower achievers. The more capable peer can help with assignments that the less capable student could not manage without this support (Wood et al. 1976). In other words, the pattern suggested by the alignment hypothesis may be suboptimal in terms of fostering academic achievement of weaker students in an FLC. A friend may not be the advanced peer contributing to others' success, because friends are likely to be similar in their achievement levels (Flashman 2012; Lomi et al. 2011).

To the extent that students focus more on improving academic achievement than attaining social goals in their relational choices in an FLC, they may differentiate types of relationships and form networks that better reflect the duality hypothesis that would be optimal according to Vygotsky's (1978) social constructive theory. Students may ask more advanced peers for academic support and make friends for non-study-related support. Given that friendship networks typically exhibit strong similarity in most characteristics of friends, this would suggest a duality hypothesis for relational patterns in an FLC. Students ask an advanced peer (higher achieving and/or more self-efficacious) for academic support but choose friends on the basis of their similarity in achievement and other relevant characteristics (e.g., gender). The duality hypothesis also implies that academic networks are asymmetric (hierarchical) and that higher-achieving and more self-efficacious students attract more requests for academic support over time. Moreover, if such a duality of relations would occur, friendships can be expected to become unrelated to academic networks over time, and some dissimilarity in 
achievement and self-efficacy between students connected in academic networks would be observed. At the same time, friendship networks should develop similarity in characteristics and exhibit reciprocated rather than asymmetric relational choices.

In sum, social network research suggests that students generally form relationships more likely when they have similar characteristics, including similar achievement (i.e., homophily). Both Tinto's (1993) model and Vygotsky's (1978) social constructivism propose normatively how peer relationships should be formed for optimally contributing to academic progress. We tested empirically to what extent the relational patterns the normative approaches of Tinto and Vygotsky favor match the reality of FLCs in our study.

\section{Method}

\section{Sample and procedure}

We obtained relational and individual-level data from 95 first-year Dutch bachelor's degree students (58 female (61.1\%); 37 male $(38.9 \%)$ ) with a mean age of 19.46 years ( $\mathrm{SD}=1.56)$. The grading system for measuring achievement runs from 0 (extremely low) to 10 (excellent). In the first semester, $53(60 \%)$ students achieved above average $(\mathrm{M}=5.97 ; \mathrm{SD}=1.96)$ and only 3 students from different learning communities scored an 8 or higher. Figure 1 shows the uneven distribution of students' achievement level. The response rate for the measurement was 93\% (three students did not respond to our survey, and four dropped out of the university). The study program has eight FLCs, with on average 12 students $(\mathrm{SD}=.35)$, within which first-year students attend all courses together in the first semester.

We collected computer-based survey and network data across two waves: at the end of the first semester and at the end of the second semester in the 2013/2014 academic year. The completion time was 20-30 min, and although students were rewarded with credit points, participation was voluntary. We informed students about the study's aims, procedure and ethical aspects. We asked them to give informed consent for us to use their study results and personal details from the central administration, to which all participants complied. In addition, the ethical committee of the degree program approved our research project.

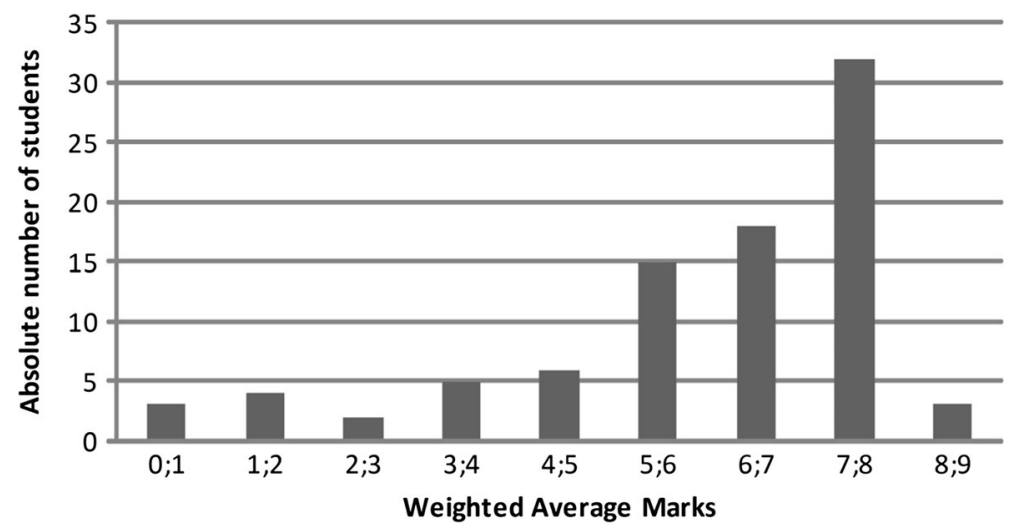

Fig. 1 Distribution of study success in the range from 0 to 9 (out of 10). $N=88$ students 


\section{Measures}

For all network questions, students could nominate all members of their cohort in the study program. Names of the members of their FLC were always listed, and respondents could enter other names. The social network questions for the peers in the FLC show automatically all the names in a complete list, i.e., roster. Students could also nominate students outside their FLC within their own study program by asking to include the name of those students, a method called free recall (Wasserman and Faust 1994). Free recall was facilitated: when they typed a part of the name, automatically some names popped up on the screen.

\section{Academic networks}

Two questions elicited academic networks: Students stated first their preference for collaboration ("I would like to collaborate with [name]") and, second, whom they would ask for help/advice of each of their fellow students ("I ask this student [name] for help when I do not understand the study material"). For both measures, students rated the nominations on a fivepoint Likert scale ( 1 = "strongly disagree", 5 = "strongly agree", 6 = "I do not know"). For the analysis, it was necessary to dichotomize the variables; we did so by recoding the categories $4=$ "agree" and $5=$ "strongly agree" as $1=$ "yes" and recoding the other categories as $0=$ "no".

\section{Friendship networks}

Respondents could nominate their fellow students as 1 = "best friend"; 2 = "friend"; 3 = "friendly relationship"; 4 = "neutral, not much in common"; 5 = "only known from face or name"; and $6=$ "I don't know who this is" (Van der Bunt 1999). To dichotomize friendship for analysis, we recoded categories 1 = "best friends," 2 = "friend," and 3 = "friendly relationships" as $1=$ "yes" and the other categories as $0=$ "no."

\section{Academic self-efficacy}

To measure academic self-efficacy ( 8 items; $\alpha=.68$ ) after the first semester, we applied the Expectancy scale of the Motivated Strategy for Learning Questionnaire (Pintrich et al. 1991). Representative items include "I think I will get good grades this block." Students responded on a scale from 1 ("strongly disagree") to 5 ("strongly agree").

\section{Achievement}

We measured achievement after the first semester as a weighted average mark. We weighted grades by the obtained credit points for a course, divided by the maximum number of credit points in the program during the first semester.

\section{Statistical analysis}

We investigated the process of relationship building in academic and friendship networks using stochastic actor-based models (Snijders 2001, 2005; Snijders et al. 2010). Testing causal factors of relational change requires longitudinal social network data. However, 
statistical analysis of such data is not possible with conventional statistical methods assuming independence of observations because, in a social network, the change of a social relation from a sender $i$ to a receiver $j$ is typically interrelated with changes in other relationships in the same network and characteristics of the individual actors involved. For example, a high-achieving student $i$ selecting another high-achieving student $j$ as a friend may do so because of their achievement similarity or because they have a shared friend. Stochastic actor-based models are increasingly applied in contemporary social network analysis (Snijders et al. 2010) to test hypotheses about the determinants of network change, controlling for effects of other simultaneous processes. These models use a combination of simulation methods with statistical model fitting. We estimated our models with the data-analysis package SIENA in R (Simulation Investigation for Empirical Network Analysis; Ripley et al. 2016), which is suitable for binary social network data in which a dyad of two students $i$ and $j$ is represented in either state 1 (relationship) or 0 (no relationship).

To test our hypotheses, we modeled the dynamics of three networks: help seeking, preference for collaboration and friendship. For each network, we estimated two models. Model 1 is the baseline model that contains model terms ("effects") controlling for several processes within one network, which commonly occurs in social network dynamics (Snijders et al. 2010). It estimates the general tendency to form relationships net of other processes (outdegree/density), whether students nominate others more if they were selected themselves more often (indegree-activity) and selected others more often (outdegreeactivity). Furthermore, model 1 tests whether a student is more likely to be nominated if he or she has already received more nominations (indegree-popularity), whether the student more likely nominates a fellow student who also chose him or her (reciprocity) or with whom the student shares a common third student they both selected (transitivity, or the tendency of friends of friends to become friends). Finally, the model tests the effects of gender (female $=1$ ) with covariate effects. The gender-ego effect estimates whether female students more likely initiate connections, and the gender-alter effect tests whether they more likely receive nominations than male students.

Model 2 adds effects to test the alignment hypothesis and the duality hypothesis. Model 2 contains two classes of effects. First, cross-network effects test whether the presence of a relationship in one network affects the likelihood of a relationship in another network. More specifically, we test how friendships affect help seeking and collaboration relationships (friendship) and whether help-seeking and collaboration relationships affect each other and friendships (pref. collaboration and help-seeking, respectively). Second, covariate effects estimate how relationships are affected by characteristics of the sender (ego), the receiver (alter) or both. An "ego-effect" means that students with higher values on the related characteristic (e.g., achievement) nominate others more often, whereas an alter effect means that those students tend to be nominated by others more often. Model 2 contains ego and alter effects for both achievement and self-efficacy, testing whether higher-achieving and more self-efficacious students more likely initiate relationships and are more often selected.

Similarity/same/higher effects assess whether relationships are more likely between students with a certain combination of characteristics. Higher effects test whether a relationship is more likely when the sender of the nomination has a higher score on the characteristic (achievement, self-efficacy) than the receiver. When students choose academically more attractive peers, this effect is evident as a negative coefficient for a higher 
effect. Same-effect (categorical variables) test homophily with regard to gender as well as whether students more likely select each other if they are in the same FLC and similarityeffect (interval-level variables) test for homophily in achievement and self-efficacy. Finally, the interaction effect achievement ego $\times$ same FLC tests whether students with higher achievement levels tend to select students outside their FLC more often.

Following Lomi et al. (2011), we also performed post hoc analyses with ego-alter tables to assess the contribution, net of other processes, of achievement of ego (student A) and alter (student B) to the likelihood (probabilities) that student A selects student B for help, collaboration or friendship. We derived these results from the coefficients for ego, alter, similarity and higher effects estimated in the second models of each network combined with the average similarity and average study success level in the first semester.

\section{Results}

\section{Descriptive statistics}

The average degree (see Table 1) indicates that in FLCs, students had fewer relationships in the second semester than in the first semester in all networks. In FLCs with around 12 students, students asked 1-3 students for help, chose 3-4 as collaborators, and identified $2-3$ as friends. The share of relationships that were reciprocated remained approximately stable in FLCs but increased in all networks outside the FLCs, indicating that changes of relationships outside the FLCs continued in the second semester. Density, or the number of directed relationships divided by the number of possible directed relationships (Wasserman and Faust 1994), is higher in FLCs than between FLCs. In the first semester, the proportion of students' help or friendship relationships are respectively $30 \%$ and $34 \%$ and for preference to collaborate $38 \%$ in their FLC, compared with only $3 \%$ in all these networks outside FLCs. The relationships in the FLCs are higher by a factor of 10 than between the FLCs. We can tentatively conclude that students relate primarily in FLCs but that as the first year progresses, help seeking and friendship networks in FLCs become less dense, whereas preference for collaboration slightly increases. The Jaccard index indicates the amount of stability in nominations between data collection points. There should be not too much fluctuation in the nominations between consecutive waves, because this would make the estimations unreliable (see for more information Snijders et al. 2010). Therefore, this metric need to be checked before starting the statistical analysis (see SIENA manual; Ripley et al. 2017). The Jaccard Similarity Index with values of .3 or higher indicates sufficient stability in the networks to estimate the statistical parameters (Snijders 2001; Snijders et al. 2010).

\section{Hypotheses testing}

The alignment hypothesis implies that students ask for academic support from their similar-achieving and similarly self-efficacious friends. Consistent with this idea, we find that dynamics in all networks are more or less similar (see Table 2 for the results). The negative outdegree parameters indicate that students are selective in their nominations; they were unlikely to initiate relationships unless they perceived their attractive properties, such as being reciprocated. All networks exhibit positive reciprocity and transitive triplets 
Table 1 Descriptive network statistics

\begin{tabular}{|c|c|c|c|c|c|c|}
\hline & \multicolumn{4}{|c|}{ Academic support networks } & \multirow{2}{*}{\multicolumn{2}{|c|}{$\begin{array}{l}\text { Friendship networks } \\
\text { Friends }\end{array}$}} \\
\hline & \multirow{2}{*}{\multicolumn{2}{|c|}{$\begin{array}{l}\text { Help seeking } \\
\text { Jaccard Similarity Index }\end{array}$}} & \multicolumn{2}{|c|}{ Preference for collaboration } & & \\
\hline & & & & & & \\
\hline & \multicolumn{2}{|l|}{0.36} & \multicolumn{2}{|l|}{0.38} & \multicolumn{2}{|l|}{0.38} \\
\hline & Semester 1 & Semester 2 & Semester 1 & Semester 2 & Semester 1 & Semester2 \\
\hline \multicolumn{7}{|c|}{ In and between FLCs } \\
\hline Average degree & 5.21 & 3.67 & 6.14 & 5.43 & 6.12 & 4.99 \\
\hline SD indegree & 3.30 & 3.02 & 3.43 & 3.94 & 3.76 & 3.68 \\
\hline SD outdegree & 3.55 & 3.02 & 3.99 & 4.02 & 4.03 & 4.03 \\
\hline Reciprocity (\%) & 36 & 48 & 37 & 49 & 41 & 50 \\
\hline Density $(\%)$ & 6 & 4 & 7 & 6 & 7 & 5 \\
\hline \multicolumn{7}{|l|}{ In FLCs } \\
\hline Average degree & 2.88 & 1.41 & 3.64 & 2.76 & 3.02 & 2.04 \\
\hline $\mathrm{SD}$ indegree & 1.67 & 1.43 & 1.82 & 2.02 & 1.74 & 1.72 \\
\hline SD outdegree & 2.45 & 1.51 & 2.78 & 2.39 & 2.60 & 2.13 \\
\hline Reciprocity (\%) & 43 & 47 & 44 & 46 & 49 & 49 \\
\hline Density $(\%)$ & 30 & 20 & 38 & 40 & 34 & 29 \\
\hline \multicolumn{7}{|l|}{ Between FLCs } \\
\hline Average degree & 2.33 & 2.26 & 2.49 & 2.67 & 3.09 & 2.95 \\
\hline SD indegree & 2.33 & 2.19 & 2.30 & 2.44 & 2.76 & 2.56 \\
\hline SD outdegree & 1.97 & 2.05 & 2.29 & 2.28 & 2.47 & 2.53 \\
\hline Reciprocity (\%) & 34 & 48 & 35 & 53 & 44 & 52 \\
\hline Density $(\%)$ & 3 & 2 & 3 & 3 & 3 & 3 \\
\hline
\end{tabular}

Note. $N=88 ; 7.744\left(88^{2}\right)$ dyads $\times 2$ waves $=15.488$ observations per network

parameters, indicating that students tend to reciprocate relational choices and to cluster in groups (i.e., to be friends with the friends of their friends). The negative transitive reciprocated triplet parameter indicates that mutual relationships are less likely in triads than in dyads. In turn, the tendency for group formation is greater when students do not have mutual relationships. Of the degree-related effects, we find consistent evidence only for a negative indegree activity effect, showing that in all networks students more frequently chosen are less likely to initiate new connections.

In line with the alignment hypothesis, we find that when students are friends, they are more likely to ask one another for help and to prefer to collaborate (positive friendship effect on academic networks). In turn, when students prefer to collaborate with one another, they are more likely to become friends (positive collaboration effect on friends). Significant effects of same gender and achievement similarity in all networks lend further support to the notion of homophily in combination with alignment, which implies that students more likely turn to their own gender and peers with similar achievement levels for academic help or friendship. In summary, we find support for the alignment hypothesis; students ask their similar-achieving friends for help or collaboration and become friends when they prefer to collaborate. However, when students ask other students for help, they are not more likely to become friends, and self-efficacy does not play a role in relationship formation in academic or friendship networks.

Support for the duality hypothesis would imply that students select not only similar peers but also slightly better peers for help or collaboration and should manifest as positive 


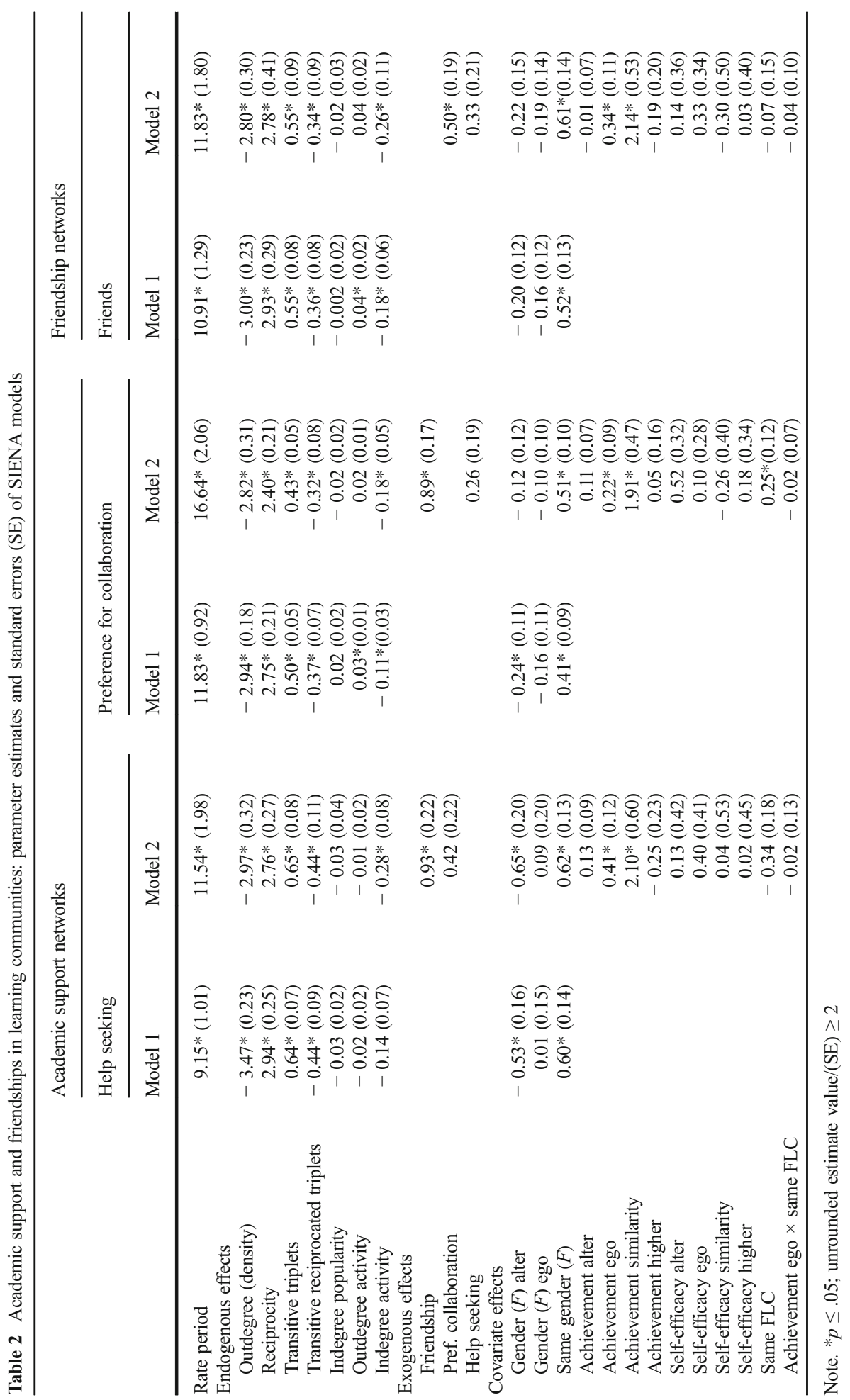


Table 3 Ego-alter table: achievement effect on probabilities (\%) of selection of academic helpers

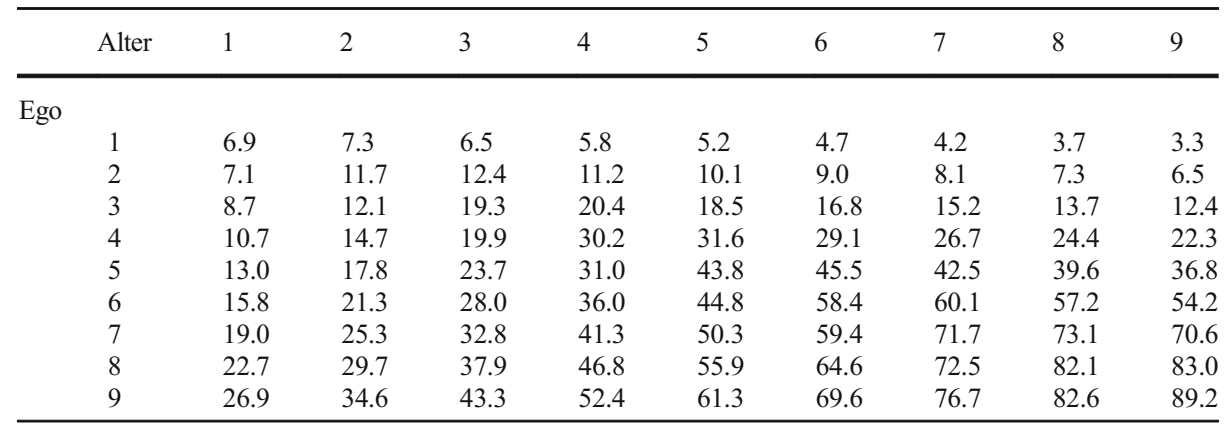

effects of similarity and negative higher effects for both achievement and self-efficacy. Our data lend no support to these expectations. We also do not find more reciprocity in the friendship networks or more hierarchy in the academic networks or any other differences in the network structures, indicating no support for the duality hypothesis.

Our results further indicate that students of the same FLC prefer to collaborate with one another (positive same-learning community effect), which might be due to joint assignment work in the FLCs during the first semester. For friendship and help seeking, we do not find that students are more likely to connect with members of their own FLC. Nor do we find that higher achievers connect with others more outside their group (achievement ego $\times$ same FLC) in any of the networks.

The probabilities in the ego-alter tables provide insight into the likelihood, net of other processes, that a student selects another for help, for collaboration or as a friend, depending on the achievement level of both students (see Tables 3, 4, and 5). For example, in Table 3 , if the potential sender of a tie is a student with a 6 (sixth row) and the potential receiver a student with a score of 7 , the model predicts an actual relation from sender to receiver with a probability of $60.1 \%$. Furthermore, students with scores 1 and 2 (first and second rows) have lower probabilities of selecting others for help than students with scores 8 and 9 (eighth and ninth rows). For help seeking, we find some evidence that students ask a slightly advanced peer. For preference for collaboration and friendship, we find achievement homophily, in that the highest probabilities occur on the diagonal of the table. In other words, in each row the probability of creating new or keeping existing connections is the highest for connections with students of the same category in terms of achievement

Table 4 Ego-alter table: achievement effect on probabilities (\%) of selection of collaborators

\begin{tabular}{|c|c|c|c|c|c|c|c|c|c|c|}
\hline & Alter & 1 & 2 & 3 & 4 & 5 & 6 & 7 & 8 & 9 \\
\hline \multicolumn{11}{|l|}{ Ego } \\
\hline & 1 & 30.7 & 27.5 & 25.4 & 23.5 & 21.6 & 19.9 & 18.2 & 16.7 & 15.3 \\
\hline & 2 & 29.9 & 36.8 & 33.2 & 30.9 & 28.7 & 26.6 & 24.6 & 22.7 & 20.9 \\
\hline & 3 & 28.0 & 35.9 & 43.3 & 39.5 & 37.0 & 34.6 & 32.2 & 29.9 & 27.8 \\
\hline & 4 & 26.3 & 33.8 & 42.3 & 50.0 & 46.2 & 43.5 & 41.0 & 38.4 & 36.0 \\
\hline & 5 & 24.6 & 31.9 & 40.2 & 49.1 & 56.8 & 53.0 & 50.3 & 47.7 & 45.0 \\
\hline & 6 & 23.0 & 30.0 & 38.1 & 46.9 & 55.9 & 63.3 & 59.6 & 57.1 & 54.5 \\
\hline & 7 & 21.5 & 28.2 & 36.0 & 44.7 & 53.7 & 62.4 & 69.4 & 66.0 & 63.6 \\
\hline & 8 & 20.0 & 26.4 & 34.0 & 42.5 & 51.4 & 60.3 & 68.6 & 74.9 & 71.8 \\
\hline & 9 & 18.6 & 24.7 & 32.0 & 40.3 & 49.2 & 58.2 & 66.6 & 74.1 & 79.6 \\
\hline
\end{tabular}


Table 5 Ego-alter table: achievement effect on probabilities (\%) of selection of friends

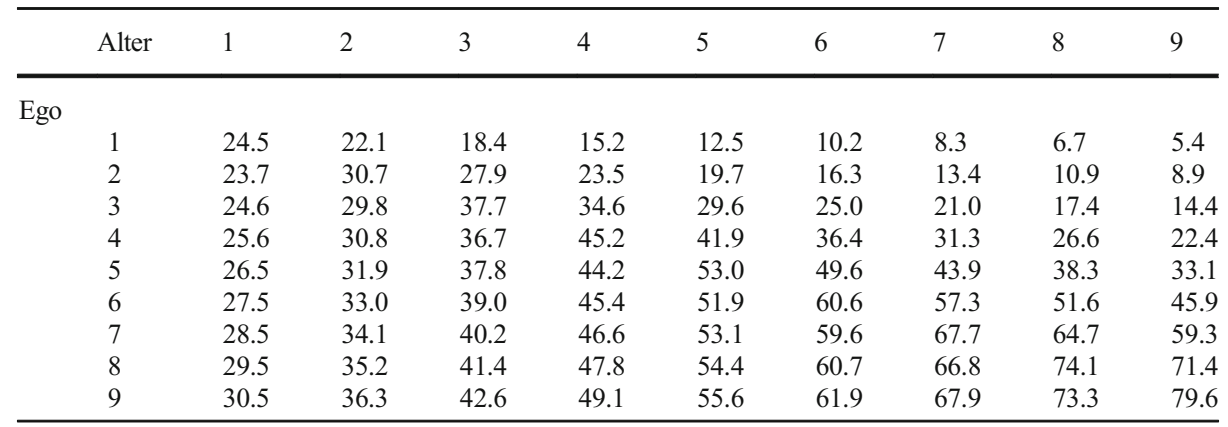

level. However, when we compared the rows in the tables, we also noted that high achievers connect more with fellow students, regardless of achievement level, reflecting the positive effects of achievement-ego in model 2 for all networks. In combination, the findings that high achievers initiate more connections and that all groups exhibit achievement homophily suggest that the networks in our FLCs are segregated by achievement. We observed more connections between high achievers than between low achievers but also more connections with low achievers initiated by high achievers than vice versa.

\section{Discussion and conclusion}

This study investigates how students connect with one another for academic support and friendship in FLCs. We contribute to the debate on how collaborative learning takes place spontaneously in FLCs. According to Tinto's (1993) interactionalist model, academic success is fostered when academic and social networks are aligned or balanced. We used research on homophily and social exchange in networks to postulate the alignment hypothesis that academic and social relationships in an FLC are largely interconnected and occur between students similar in achievement levels and self-efficacy. From the perspective of Vygotsky's (1978) theory, such a pattern may be suboptimal for academic progress, as students benefit from academic support from more advanced peers as well. We formulated the duality hypothesis that if students are to some extent instrumental in their relational choices, they connect more with higher-achieving fellow students for academic support and not with their similar-achieving friends, separating academic and social networks in the process.

To our knowledge, this study is the first to assess the dynamics of social and academic relationships in FLCs with stochastic actor-based models. These models allow us to disentangle the effects of simultaneous processes in the formation of social networks. We found support for the alignment hypothesis but not for the duality hypothesis. The determinants of network choices are more or less similar in social and academic relationships, and when students are friends, they are more likely to ask each other for academic support. In turn, when students prefer to collaborate, they are also more likely to be friends. Consistent with the finding of Lomi et al. (2011), we find a tendency for achievement homophily (but not for selfefficacy) for friendship and in the academic networks. This implies that lower achievers provide academic support primarily to and become friends with one another, and the same holds for higher-achieving students. In contrast with Lomi et al. (2011), who find in one group 
of 75 students that high achievers have less friendship relationships, we found that higher achievers have more friendships and academic relationships, though they connect even more with higher-achieving fellow students. This difference suggests that FLCs foster the alignment of networks and, in particular, for higher achievers. That students are more likely to ask their friends for academic support suggests that lower-achieving students prefer the availability of and timely access to the information rather than the expertise, because friends are most likely similar-achieving students. The higher-achieving students may prefer the timely access to the information, but they may also appreciate the expertise of the other (Borgatti and Cross 2003) and may expect a valuable return as proposed by social exchange theory (e.g., Blau 1964; Cook and Rise 2003; Homans 1961).

Although universities have implemented FLCs with the intent of enhancing interactions among students, we found that as a result of network alignment, networks become segregated in terms of achievement levels. The segregation effect, like the Matthew effect (Merton 1968), implies that higher-achieving students can benefit the most from learning communities. This effect can even be reinforced because these students have more connections and can also learn from explaining study material to lower achievers (Webb 1991). Lower-achieving students do not connect with advanced peers and have fewer connections that might be useful to improve their achievement. These results are consistent with our recent findings that high achievers benefit more from their friends for study success than low achievers (Brouwer et al. 2016b). What makes lower achievers connect less with others when these connections would be quite useful? First, lower achievers may have difficulties in approaching their fellow students if they do not have the social skills necessary for asking support (Cleland et al. 2005; Todres et al. 2012; Vaughan et al. 2015). Second, lower achievers may be excluded from the support of higher achievers when higher achievers select each other for academic support and only lower achievers remain available for lower achievers. This latter explanation is in line with emergent segregation patterns found in theoretical research on the evolution of helpexchange networks among actors with unequal capacities and neediness for help (Flache and Hegselmann 1999).

A limitation of this study is that we could not rule out the scenario that lower achievers preferred higher achievers, but that these students were unwilling or unavailable to help. Further research with qualitative data, such as interviews, would provide insight into the motivation behind students' relational choices. A potential methodological limitation of our study could also be that the nomination process of peers used for the network questions somewhat skews results towards naming individuals within the FLC. The availability of full lists of names for FLC peers could have focused students' attention more on the FLC. While this possibility cannot be fully excluded, we believe that the problem is small. Students meet their FLC peers regularly and frequently and therefore are unlikely to forget them. Moreover, our procedure has assured that also individuals outside an FLC could be nominated with relatively little effort. We believe that this is a good compromise because it is practically impossible to let student select names from a list of about 500 peers. A last potential limitation could be that we used one relatively small study program. Investigating networks in different study programs would further generalize our results. In relatively small programs, students tend to know one another well beyond the boundaries of the FLCs. We expect that in a largesized study program, students may be more focused on their own group. Additional research could shed light on this supposition. 
The results suggest achievement segregation in FLCs, which is a concern for all students because connection with an advanced peer in Vygotsky's (1978) zone of proximal development may fail. A low achiever might not gain from a similar achiever's academic support, and high achievers may not gain because they are already close to the ceiling of their learning curve (Day et al. 2005). Universities might include peer-assisted learning within small-group teaching contexts (e.g., Furmedge et al. 2014) to encourage students to collaborate with their slightly advanced peers to prevent achievement segregation in FLCs. Further research in the university context should investigate small-group compositions and peer tutoring to determine whether student capabilities are maximally fostered. Other studies in primary or secondary education show that low-ability students learn the most in heterogeneous ability groups, average achievers in homogeneous groups and high achievers in both homogeneous and heterogeneous groups (Saleh et al. 2005; Webb 1991; Webb et al. 2002). However, these studies do not take into account the interplay of changes in relationships and achievement development. To shed more light on the impact of changing relationships on achievement development of first-year university students, we recommend investigating this phenomenon with longitudinal social network analysis in small groups.

In this study, we found support for the alignment hypothesis that relational structures resemble the alignment Tinto's (1993) interactionalistic model sees as ideal for academic progress and not the duality of relations Vygotsky's (1978) social constructivism favors. This suggests that more mentoring dyads should be created to induce social structures that match better with the optimal relational pattern proposed by Vygotsky's social constructivism. For example, with reciprocal peer tutoring students exchange information in a structured way by taking either the role of tutor or the tutee Lueg et al. 2016. Students create knowledge constructively by asking questions, clarifying study material, and providing feedback (Chi et al. 2001; Topping 2005). Higher-achieving students can be assumed to have the expertise their lower-achieving peers need to obtain, because high achievers have shown to understand the study material well. This suggests that - all others things being equal — students in need of academic help could prefer higher-achieving peers as source of help, an assumption that we could test in our research. However, it might also be that a higher achiever cannot give support within the zone of proximal development of the lower-achieving peer. Connecting students during (reciprocal) peer tutoring does not result automatically in deep learning. On the contrary, the outcome and quality of peer tutoring may depend on factors, such as prior achievement, motivation, and training about feedback strategies and to collaborate in small groups (Barron 2003; Webb 2009). De Backer et al. (2017) find that when trained participants tutor their peers the tutors show an increase in deep-level learning approach and thoughtprovoking questioning which resulted in discussions between tutor and tutee in which they respond on each other's cognitive and metacognitive contributions. Buchs and Butera (2009) show that feedback provided by a higher-achieving peer is only beneficial when the transferred knowledge is complementary. Students need to learn strategies how to explain study material and give feedback in order to enhance the effectiveness and quality of peer tutoring (Van Ginkel et al. 2017). Our data did not allow assessing complementarity of knowledge, but future research could explore to what extent the effects of expertise difference on relationship formation that we have found are modified when knowledge complementarity and individual characteristics related to scaffolding strategies are taken into account.

In conclusion, we found that academic and friendship networks are aligned with a nuanced pattern in terms of achievement; in the FLCs, higher achievers connect more often with others for academic support and friendship. We found a tendency for 
achievement homophily and emergent achievement segregation. The results suggest that higher achievers benefit most from the FLC because they can obtain valuable advice and help or benefit from explaining the study material to others. This achievement segregation may be detrimental for reaching the potential of all students, and therefore actively matching students for peer tutoring in FLCs is important.

Acknowledgements We are grateful to Wilmer Joling for his technical expertise and support in this Learning Communities research project of the University of Groningen, the Netherlands.

Open Access This article is distributed under the terms of the Creative Commons Attribution 4.0 International License (http://creativecommons.org/licenses/by/4.0/), which permits unrestricted use, distribution, and reproduction in any medium, provided you give appropriate credit to the original author(s) and the source, provide a link to the Creative Commons license, and indicate if changes were made.

\section{References}

Aleven, V., Stahl, E., Schworm, S., Fischer, F., \& Wallace, R. (2003). Help seeking and help design in interactive learning environments. Review of Educational Research, 73(3), 277-320.

Bandura, A. (1997). Self-efficacy: the exercise of control. New York: Cambridge University Press.

Barron, B. (2003). When smart groups fail. The Journal of the Learning Sciences, 12, 307-359.

Beekhoven, S., De Jong, U., \& Van Hout, H. (2002). Explaining academic progress via combining concepts of integration theory and rational choice theory. Research in Higher Education, 43(5), 577-600.

Blau, P. M. (1964). Exchange and power in social life. New York: Wiley.

Borgatti, S. P., \& Cross, R. (2003). A relational view of information seeking and learning in social networks. Management Science, 49(4), 432-445. https://doi.org/10.1287/mnsc.49.4.432.14428.

Brooman, S., \& Darwent, S. (2014). Measuring the beginning: a quantitative study of the transition to higher education. Studies in Higher Education, 39(9), 1523-1541. https://doi.org/10.1080/03075079.2013.801428.

Brouwer, J., Jansen, E., Hofman, A., \& Flache, A. (2016a). Early tracking or finally leaving? Determinants of early study success in first-year university students. Research in Post-Compulsory Education, 21(4), 376393. https://doi.org/10.1080/13596748.2016.1226584.

Brouwer, J., Jansen, E., Flache, A., \& Hofman, A. (2016b). The impact of social capital on self-efficacy and study success among first-year university students. Learning and Individual Differences, 52, 109-118. https://doi.org/10.1016/j.lindif.2016.09.016.

Brown, S. A., Street, D., \& Martin, J. P. (2014). Engineering student social capital in an interactive learning environment. International Journal of Engineering Education, 30(4), 813-821.

Buchs, C., \& Butera, F. (2009). Is a partner's competence threatening during dyadic cooperative work? It depends on resource interdependence. European Journal of Psychology of Education, 24(2), 145-154.

Buote, V. M., Pancer, S. M., Pratt, M. W., Adams, G., Birnie-Lefcovitch, S., Polivy, J., \& Wintre, M. G. (2007). The importance of friends: friendship and adjustment among 1st-year university students. Journal of Adolescence Research, 22(6), 665-689. https://doi.org/10.1177/0743558407306344.

Celant, S. (2013). The analysis of students' academic achievement: the evaluation of peer effects through relational links. Quality \& Quantity, 47, 615-631. https://doi.org/10.1007/s11135-011-9536-8.

Chen, B., Wang, F., \& Song, J. (2012). Are they connected? Exploring academic and social networks among MPA students at a Chinese university. Journal of Public Affairs Education, 18(1), 137-156.

Chi, M. T. H., Siler, S. A., Jeong, H., Yamauchi, T., \& Hausmann, R. G. (2001). Learning from human tutoring. Cognitive Science, 25(4), 471-533. https://doi.org/10.1016/S0364-0213(01)00044-1.

Christie, H., Munro, M., \& Fisher, T. (2004). Leaving university early: exploring the differences between continuing and non-continuing students. Studies in Higher Education, 29(5), 617-636. https://doi. org/10.1080/0307507042000261580.

Cleland, J., Arnold, R., \& Chesser, A. (2005). Failing finals is often a surprise for the student but not the teacher: identifying difficulties and supporting students with academic difficulties. Medical Teacher, 27(6), 504-508. https://doi.org/10.1080/01421590500156269.

Cook, K. S., \& Rise, E. (2003). Social exchange theory. In J. Delamater (Ed.), Handbook of social psychology (pp. 53-76). New York: Kluwer Academic/Plenum Publishers.

Cross, R., \& Borgatti, S. P. (2004). The ties that share: relational characteristics that facilitate information seeking. In M. Huysman \& V. Wulf (Eds.), Social capital and information technology (pp. 137-161). Cambridge: The MIT press. 
Day, E. A., Arthur Jr., W., Bell, S. T., Edwards, B. D., Bennett Jr., W., Mendoza, J. L., \& Tubré, T. C. (2005). Ability-based pairing strategies in the team-based training of a complex skill: does the intelligence of your training partner matter? Intelligence, 33, 39-65. https://doi.org/10.1016/j.intell.2004.09.002.

De Backer, L., Van Keer, H., \& Valcke, M. (2017). Is collaborative learners' adoption of metacognitive regulation related to students' content processing strategies and the level of transactivity in their peer discussions? European Journal of Psychology of Education, 32, 617-642. https://doi.org/10.1007/s10212-016-0323-8.

Etcheverry, E., Clifton, R. A., \& Roberts, L. W. (2001). Social capital and educational attainment: a study of undergraduates in a faculty of education. Alberta Journal of Educational Research, 47(1), 24-39.

Feldman, D. B., \& Kubota, M. (2015). Hope, self-efficacy, optimism, and academic achievement: distinguishing constructs and levels of specificity in predicting college grade-point average. Learning and Individual Differences, 37(6), 210-216. https://doi.org/10.1016/j.lindif.2014.11.022.

Flache, A., \& Hegselmann, R. (1999). Rationality vs. learning in the evolution of solidarity networks: a theoretical comparison. Computational \& Mathematical Organization Theory, 5(2), 97-127.

Flashman, J. (2012). Academic achievement and its impact on friend dynamics. Sociology of Education, 85(1), 61-80. https://doi.org/10.1177/0038040711417014.

Furmedge, D. S., Iwata, K., \& Gill, D. (2014). Peer-assisted learning-beyond teaching: how can medical students contribute to the undergraduate curriculum? Medical Teacher, 36(9), 812-817. https://doi. org/10.3109/0142159X.2014.917158.

Gaševic, D., Zouaq, A., \& Janzen, R. (2013). Choose your classmates, your GPA is at stake! The association of cross-class social ties and academic performance. American Behavioral Scientist, 57(10), 1460-1479. https://doi.org/10.1177/0002764213479362.

Homans, G. C. (1961). Social behavior and its elementary forms. New York: Harcourt, Brace and World.

Kraft, P., Rise, J., Sutton, S., \& Røysamb, E. (2005). Perceived difficulty in the theory of planned behaviour: perceived behavioural control or affective attitude? British Journal of Social Psychology, 44, 479-496. https://doi.org/10.1348/014466604X17533.

Lomi, A., Snijders, T. A. B., Steglich, C. E. G., \& Torló, V. J. (2011). Why are some more peers than others? Evidence from a longitudinal study of social networks and individual academic performance. Social Science Research, 40, 1506-1520. https://doi.org/10.1016/j.ssresearch.2011.06.010.

Lueg, R., Lueg, K., \& Lauridsen, O. (2016). Aligning seminars with Bologna requirements: reciprocal peer tutoring, the solo taxonomy and deep learning. Studies in Higher Education, 41(9), 1674-1691. https://oi. org/10.1080/03075079.2014.1002832.

McPherson, M., Smith-Lovin, L., \& Cook, J. M. (2001). Birds of a feather: homophily in social networks. Annual Review of Sociology, 27, 415-444.

Meeuwisse, M., Severiens, S. E., \& Born, M. P. (2010). Learning environment, interaction, sense of belonging and study success in ethnically diverse student groups. Research in Higher Education, 51, 528-545. https://doi.org/10.1007/s11162-010-9168-1.

Merton, R. K. (1968). The Matthew effect in science. Science, 159(3810), 56-63.

Mizruchi, M. S., \& Stearns, L. B. (2001). Getting deals done: the use of social networks in bank decision-making. American Sociological Review, 66(5), 647-671.

Nebus, J. (2006). Building collegial information networks: a theory of advice network generation. The Academy of Management Review, 31(3), 615-637.

O'Donnell, A. M. (2006). The role of peers and group learning. In P. A. Alexander \& P. H. Winne (Eds.), Handbook of educational psychology (2d ed., pp. 781-802). New York: Routledge.

Pintrich, P. R., Smith, D. A. F., Garcia, T., \& McKeachie, W. J. (1991). A manual for the use of the motivated strategies for learning questionnaire (MSLQ). Ann Arbor: National Centre for Research to Improve Postsecondary Teaching and Learning.

Rausch, J. L., \& Hamilton, M. W. (2006). Goals and distractions: explanations of early attrition from traditional university freshmen. The Qualitative Report, 11(2), 317-334.

Richardson, M., Abraham, C., \& Bond, R. (2012). Psychological correlates of university students' academic performance: a systematic review and meta-analysis. Psychological Bulletin, 138(2), 335-387. https://oi. org/10.1037/a0026838.

Rienties, B., Héliot, Y., \& Jindal-Snape, D. (2013). Understanding academic performance of international students: the role of ethnicity, academic and social integration. Higher Education, 66, 489-504. https://doi.org/10.1007/s10734-013-9617-9.

Ripley, R. M., Snijders, T. A., Boda, Z., Vörös, A., \& Preciado, P. (2017). Manual for RSiena. Oxford: University of Oxford, Department of Statistics; Nuffield College. Derived from: http://www.stats.ox.ac. uk/ snijders/siena/RSiena_Manual.pdf.

Saleh, M., Lazonder, A. W., \& De Jong, T. (2005). Effects of within-class ability grouping on social interaction, achievement, and motivation. Instructional Science, 33, 105-119. https://doi.org/10.1007/s11251-004-6405-z. 
Severiens, S., \& Wolff, R. (2008). A comparison of ethnic minority and majority students: social and academic integration, and quality of learning. Studies in Higher Education, 33(3), 253-266. https://doi.org/10.1080 /03075070802049194.

Smith, R. A. (2015). Magnets and seekers: a network perspective on academic integration inside two residential communities. Journal of Higher Education, 86(6), 893-922. https://doi.org/10.1353/jhe.2015.0033.

Smith, B., MacGregor, J., Matthews, R. S., \& Gabelnick, F. (2004). Learning communities: reforming undergraduate education. San Francisco: Jossey-Bass.

Snijders, T. A. B. (2001). The statistical evaluation of social network dynamics. In M. Sobel \& M. Decker (Eds.), Sociological methodology (pp. 361-395). Boston: Basil Blackwell.

Snijders, T. A. B. (2005). Models for longitudinal data. In P. J. Carrington, J. Scott, \& S. Wasserman (Eds.), Models and methods in social network analysis (pp. 215-247). New York: Cambridge University Press.

Snijders, T. A. B., Van der Bunt, G. G., \& Steglich, C. E. G. (2010). Introduction to stochastic actor-based models for network dynamics. Social Networks, 32, 44-60.

Talburt, S., \& Boyles, D. (2005). Reconsidering learning communities: expanding the discourse by challenging the discourse. Journal of General Education, 54(3), 209-236. https://doi.org/10.1353/jge.2006.0007.

Thomas, S. L. (2000). Ties that bind: a social network approach to understanding student integration and persistence. Journal of Higher Education, 71(5), 591-615.

Tinto, V. (1975). Dropout from higher education: a theoretical synthesis of recent research. Review of Educational Research, 45(1), 89-125.

Tinto, V. (1993). Leaving college. Rethinking the causes and cures of student attrition (2nd ed.). Chicago: The University of Chicago Press.

Tinto, V. (1998). Colleges as communities: taking research on student persistence seriously. The Review of Higher Education, 21(2), 167-177.

Tinto, V. (2000). Exploring the role of the college classroom in student departure. In J. M. Braxton (Ed.), Reworking the student departure puzzle (pp. 81-94). Nashville: Vanderbilt University Press.

Todres, M., Tsimtsiou, Z., Sidhu, K., Stephenson, A., \& Jones, J. (2012). Medical students' perceptions of the factors influencing their academic performance: an exploratory interview study with high-achieving and resitting medical students. Medical Teacher, 34(5), 325-331. https://doi.org/10.3109/0142159X.2012.668626.

Tomás-Miquel, J.-V., Expósito-Langa, M., \& Nicolau-Juliá, D. (2015). The influence of relationship networks on academic performance in higher education: a comparative study between students of a creative and a noncreative discipline. Higher Education, 71(3), 307-322. https://doi.org/10.1007/s10734-015-9904-8.

Topping, K. J. (2005). Trends in peer learning. Educational Psychology, 25, 631-645. https://doi.org/10.1080 /01443410500345172.

Torenbeek, M., Jansen, E., \& Hofman, A. (2010). The effect of the fit between secondary and university education on first-year student achievement. Studies in Higher Education, 35(6), 659-675. https:/doi. org/10.1080/03075070903222625.

Townsend, S. S. M., Kim, H. S., \& Mesquita, B. (2014). Are you feeling what I'm feeling? Emotional similarity buffers stress. Social Psychological and Personality Science, 5(5), 526-533. https://doi.org/10.1177 /1948550613511499.

Van der Bunt, G. G. (1999). Friends by choice: an actor-oriented statistical network model for friendship networks through time. Doctoral dissertation, University of Groningen, Groningen, The Netherlands.

Van Ginkel, S., Gulikers, J., Biemans, H., \& Mulder, M. (2017). Fostering oral presentation performance: does the quality of feedback differ when provided by the teacher, peers or peers guided by tutor? Assessment \& Evaluation in Higher Education, 42(6), 953-966. https://doi.org/10.1080/02602938.2016.1212984.

Vaughan, S., Sanders, T., Crossley, N., O’Neill, P., \& Wass, V. (2015). Bridging the gap: the roles of social capital and ethnicity in medical student achievement. Medical Education, 49(1), 114-123. https://doi.org/10.1111 /medu.12597.

Vygotsky, L. S. (1978). Mind in society: the development of higher psychological processes. Cambridge: Harvard University Press.

Wasserman, S., \& Faust, K. (1994). Social network analysis: methods and applications. Cambridge: Cambridge University Press.

Webb, N. M. (1991). Task-related verbal interaction and mathematics learning in small groups. Journal for Research in Mathematics Education, 22(5), 366-389.

Webb, N. M. (2009). The teacher's role in promoting collaborative dialogue in the classroom. British Journal of Educational Psychology, 79, 1-28.

Webb, N. M., Nemer, K. M., \& Zuniga, S. (2002). Short circuits or superconductors? Effects of group composition on high-achieving students' science assessment performance. American Educational Research Journal, 39(4), 943-989. 
Wilcox, P., Winn, S., \& Fyvie-Gauld, M. (2005). "It was nothing to do with the university, it was just the people": the role of social support in the first-year experience of higher education. Studies in Higher Education, 30(6), 707-722. https://doi.org/10.1080/03075070500340036.

Wood, D., Bruner, J. S., \& Ross, G. (1976). The role of tutoring in problem solving. Journal of Child Psychology and Psychiatry, 17, 89-100.

Zhao, C.-M., \& Kuh, G. D. (2004). Adding value: learning communities and student engagement. Research in Higher Education, 45(2), 116-138.

Zhu, X., Woo, S. E., Porter, C., \& Brzezinski, M. (2013). Pathways to happiness: from personality to social networks and perceived support. Social Networks, 35, 382-393. https://doi.org/10.1016/j. socnet.2013.04.005. 